\title{
Effects of Interaction on Reading Comprehension in the Secondary School Classrooms: An Action Research
}

By Md. Nasim Fardose Sajib \& Nurun Nahar

World University of Bangladesh

Abstract- This study investigates the EFL classrooms to identify the role of interaction in reading comprehension classes. Student-student interaction through the form of pair-work was introduced while the pre-test and post-test measured its effect. Adequate classes were observed to identify the level of the control group students. This study tried to find out the role of interaction in facilitating students' reading comprehension. It had found that when the students got the opportunity to interact through pair-work, they became their source of input. And it was evident that after the introduction of interaction, their comprehension ability enhanced as they correctly answered more questions in the post-test than in the pre-test. Based on the results, the study also recommends the introduction of interaction to enhance students' skill in listening, speaking, and writing.

Keywords: interaction, reading comprehension, pair work, EFL classrooms, secondary school. GJHSS-A Classification: FOR Code: 130106

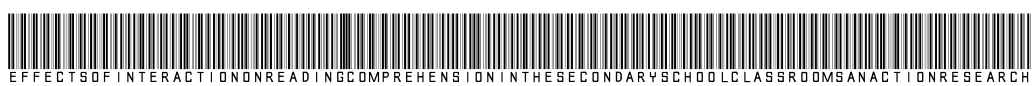

Strictly as per the compliance and regulations of:

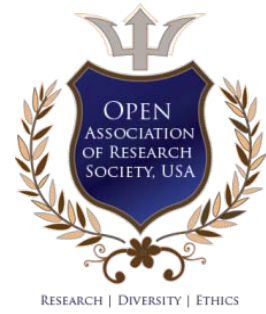

(c) 2020. Md. Nasim Fardose Sajib \& Nurun Nahar. This is a research/review paper, distributed under the terms of the Creative Commons Attribution-Noncommercial 3.0 Unported License http://creativecommons.org/licenses/by-nc/3.0/), permitting all noncommercial use, distribution, and reproduction in any medium, provided the original work is properly cited. 


\title{
Effects of Interaction on Reading Comprehension in the Secondary School Classrooms: An Action Research
}

\author{
Md. Nasim Fardose Sajib ${ }^{\alpha}$ \& Nurun Nahar ${ }^{\sigma}$
}

\begin{abstract}
This study investigates the EFL classrooms to identify the role of interaction in reading comprehension classes. Student-student interaction through the form of pairwork was introduced while the pre-test and post-test measured its effect. Adequate classes were observed to identify the level of the control group students. This study tried to find out the role of interaction in facilitating students' reading comprehension. It had found that when the students got the opportunity to interact through pair-work, they became their source of input. And it was evident that after the introduction of interaction, their comprehension ability enhanced as they correctly answered more questions in the post-test than in the pre-test. Based on the results, the study also recommends the introduction of interaction to enhance students' skill in listening, speaking, and writing.
\end{abstract}

Keywords: interaction, reading comprehension, pair work, EFL classrooms, secondary school.

\section{InTRODUCTION}

n Bangladesh, Bangla is entertained as the official language, and there is no reference of the second language in the language policy. And this is because of the vivid, tragic, but inspiring language history where the people in this region were martyred during a language movement in 1952. All the languages except Bangla are considered as a foreign language here. But among them, the English language gets a higher value in the education, social, and economic sectors because of its global status and appeal. The connection between the English language and Bangladesh is old, as Bangladesh was the subcontinent of British colonization. The role of English has always been vital here. And it is evident because English is a compulsory subject from the very early part of education for the Bangladeshi students. Besides English bears the status of linguafranca in almost all sectors. This type of affiliation with English language inspires the learners as well as the government stakeholders to take the learning of this language seriously. Many types of research, studies, and workshops are being conducted to make the learners competent. In this regard, this study tries to focus on reading comprehension through action research to have a close look on the issue from the root

Author $\alpha$ : Senior Lecturer in the Department of English at World University of Bangladesh.e-mail:m.n.f.sajib@gmail.com

Author $\sigma$ : Senior Lecturer in the Department of English at World University of Bangladesh.e-mail:naharnrekha@gmail.com level. During classroom observation, the lack of exposure and proper communication are identified, which are the pre-conditions to be skilled in a language. Learners need the opportunity to negotiate. Both Long (1981) and Ellis (1990)(Cited in Ellis, Tanaka, and Yamazaki 1994, p450) acknowledge that when the learners of second language face problems during communication and the opportunity to negotiate solutions are presented to them, they become more capable of acquiring a new language. That is why the need for interaction is highlighted in this study. Besides, interaction is a very natural process for any individual, which develops in the early stage on the social level. According to Vygotsky (1978, p57), "Every function in the child's cultural development appears twice: first, on the social level, and later, on the individual level; first, between people (interpsychological) and then inside the child (intrapsychological)."

In this regard, the learners of class VII were chosen as the participants of this research. Because they are young, and they need more exposure to have more comprehensible input to learn the English language. Krashen framed comprehensible input as the only causative variable in SLA (Krashen, 1981, p57) in his monitor model. That is why the effect of interaction was needed to appraise during reading comprehension lessons to identify the role of comprehensible input.

Among the language skills, reading skill develops learners understanding of the given information through written discourse. It carries great importance to learn a foreign language. Reading skill is the most important and useful skill which contributes to developing all the four language skills. By enhancing reading comprehension, the learners not only will be competent in reading skills but also in writing, speaking, and listening skills. It is connected to all the four skills of language learning. Krashen \& Terrel (1983, p131) state that, "Reading may contribute significantly to competence in a second language. There is good reason, in fact, to hypothesize that reading makes a contribution to overall competence, to all four skills." Besides, by developing reading comprehension, the learners understand, evaluate, and utilize the information (Smith \& Johnson, 1978, p56). But the learners' involvement is rarely found in the EFL classrooms. And the teachers do not have much application to engage 
the learners during reading comprehension lessons. Teacher-students or students-students interaction rarely takes place in the Bangladeshi EFL classrooms. So, facilitation of comprehensible input remains invisible in those classes. As the teachers fail to facilitate comprehensible input during reading comprehension lessons, learners' exposure to reading skills as well as learning the language fails to develop. Pair work as the medium of interaction is introduced as it allows the learners to work and interact independently. (Harmer, 2007, p165).

In this regard, this study seeks the answer to the following question.

How far does interaction facilitate comprehensible input in reading comprehension lessons in the EFL classrooms?

This study also proposes the following hypothesis.

- In the Bangla medium EFL classrooms, learners, especially the students of class VII, may perform better, if they interact during reading comprehension lessons.

- Through Interaction, it may be possible to augment more comprehensible input of reading comprehension.

\section{Literature RevieW}

The role of input is inevitable for acquiring a second language or foreign language. Ellis (1985, p12) opine that 'SLA can take place only when the learner has access to $L 2$ input.' But to make it useful for $F L$ learners, the input should be comprehensible. According to Yule (2006, p191), input has to be comprehensible to be beneficial for $\mathrm{L} 2$ learning. Krashen (1985, p2) also signifies the role of comprehensible input as he states, "The Input Hypothesis claims that human acquire language in only one way - by understanding messages, or by receiving comprehensible input." Harmer (2007, p266) also shows a connection between comprehensible input and learning the English language. The more the message will be comprehensible, the more learning will take place in an L2 learning context. Accepting the role of comprehensible input, Van Lier (2004, p141) states, "A more active and interactive perspective on input holds that we can make the language more comprehensible by engaging in meaningful interaction." And to make that happen, negotiation for meaning needs to be established in that context. Long (1996, p418), considers negotiation for meaning as the process where learners and competent speakers provide and interpret signals of their own, and their interlocutors receive comprehension till a minimum level of understanding achieved. And that negotiation works when there is an interaction between non-native speakers (NNS) and native speakers (NSs) or more competent interlocutors; such negotiation facilitates acquisition because it connects input, internal learner capacities, particularly selective attention, and output in productive ways (Khatib, Alemi \& Daftarifard, 2010, p63). But only social interaction is not enough. Rather, additional perspectives on dynamic interactions of all levels are also necessary (Ellis, N. 2009, p31). Interaction in the classrooms can be an option for such perspectives. MacLeod and Maclntyre(1977, p266) consider interaction as one of the striking features of a classroom. Because it can be beneficial for the learners, especially for the ESL or EFL learners as it promotes communication through meaning, which is the primary means of a language. Gass \& Mckey (2006, cited in Oliver, 2009, p135) find a robust connection between interaction and learning. Pica (1994, p494) also denotes that interaction takes place when learners and their interlocutors anticipate, perceive, or experience challenges to comprehend the messages. He also states, "As they negotiate, they work linguistically to achieve the needed comprehensibility, whether repeating a message verbatim, adjusting its syntax, changing its words, or modifying its form and meaning in a host of other ways (Pica, 1994, p494)."

According to Ellis, Tanaka, and Yamazaki's article (cited in Salazar \& Filologia, 1996, p4,) the learners who receive input through interaction achieve more L2 comprehension than those who are exposed to other types of input. Khatib, Alemi, \& Daftarifard,(2010) also agree about the importance of engagement towards language development. They state, "While being engaged in challenging tasks, learners need to work actively to comprehend each other's messages, and in this work they focus on those parts of language that need improvement, both receptively and productively (Khatib, Alemi, \& Daftarifard, 2010, p63)."

\section{ili. Research Design and Methodology}

The Quantitative approach was chosen to conduct the study to have more reliable and objective data. Experimental research design was introduced as baseline collection data is attainable, and researcher gets the normative point of reference through it (Ellis, 1994, p245). The complete design of the research is as follows:

The main stakeholders of this study are the students of class VII. Five high schools from Dhaka city were chosen based on the researcher's access and capacity to collect data for this study. It was also important to mention that the medium of instruction is Bengali in those particular schools. The size of sample group students is 67 in number. The age group of the students is between 11 and 14 years. The class size of five different classrooms in those schools is between 11 and 15.

According to the experimental design, a pre-test and a post-test were chosen as instruments to conduct 
the research. The pre-test was introduced to measure the current proficiency level of the students and the post-test to measure the reading comprehension in order to identify the effect of interaction through peer interaction format which was introduced in between the tests as the treatment. Pair-work as a form of peer interaction was introduced because of the traditional classroom decoration and seating arrangement in those classrooms. It is important to mention that in the cases of odd number participants in those classrooms, the researcher took the liberty to make a group of having three students rather arranging a pair. True-false and short answer types of question items were chosen for both the tests though questions were different. Questions were based on two different but similar types of passages respectively in the pre-test and post-test. It is also important to mention that adequate classes were observed before choosing such instruments for this particular study. The same procedure was repeated in all the target classrooms to have minimum varieties in collecting data.

\section{a) Data Collection}

To initiate experimental design, a pre-test (Appendix A) based on reading comprehension was introduced containing the test items of true/false and short answer to measure the current level of proficiency the control group students. But before introducing the test, adequate classes were observed too. The objectives of the research were also taken into consideration while choosing the question types. Considering the time constraints, five questions were listed under each category. Then students were familiarized with interaction through adequate information, demonstration, and practice on peer interaction. After that, a new reading lesson was introduced. This time peer-interaction in the form of pairwork took place alongside the traditional class. At the end of the class, a post-test (Appendix B) was introduced with similar test items and the exact same number of questions, but the questions were different. It also needs to mention that the level of the test items was constant to gather authentic results for this study. A similar procedure was maintained in all the five classrooms.

\section{b) Data Analysis}

The test results of both pre-test (Appendix A) and post-test (Appendix B) were considered for analyzing the data for this study. The data represent the performances of the control group students both before and after the introduction of interaction through the form of peer-interaction in the reading comprehension lessons. The following data also shows the average and comparison of their performances in the pre-test and post-test.

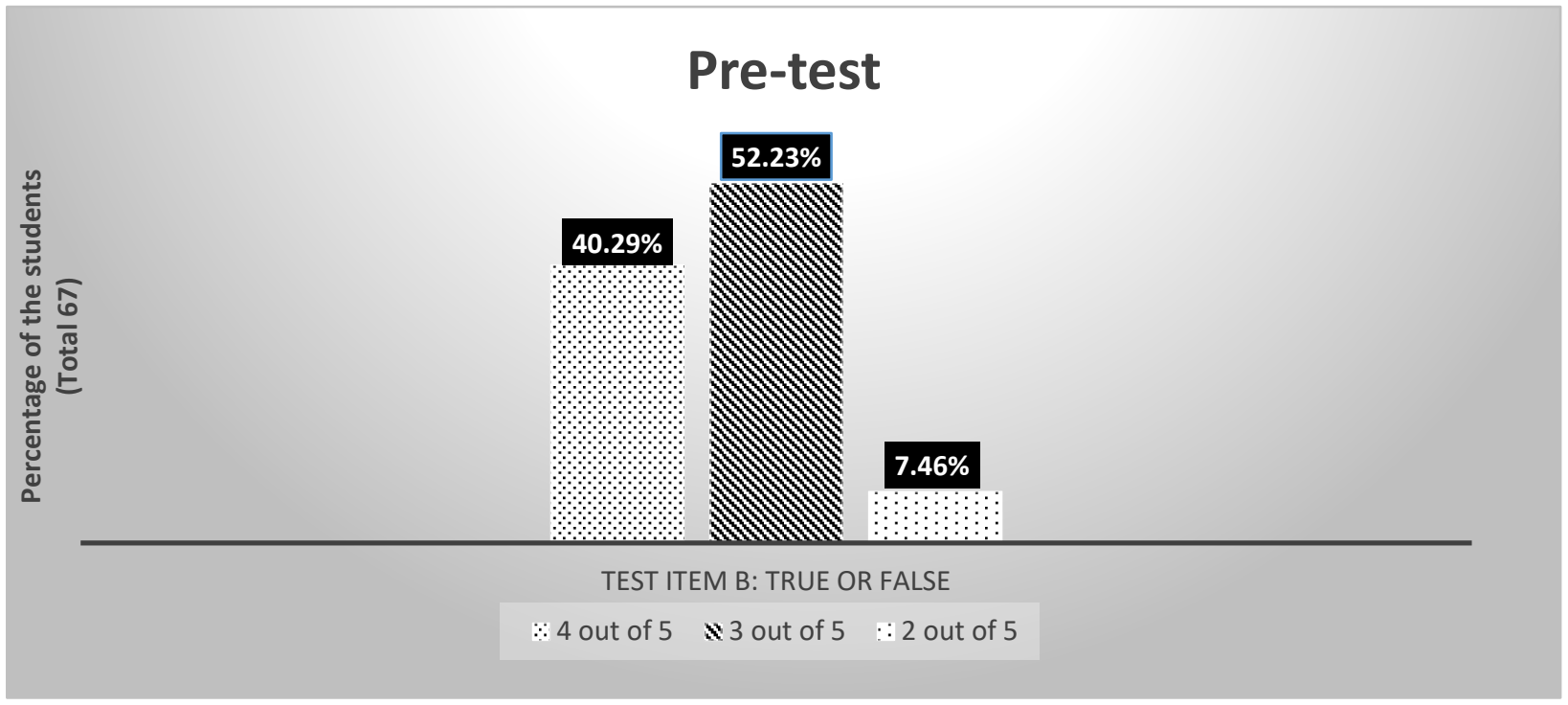

Figure 1: Students' performance regarding their ability to answer correctly in the pre-test: Test item B:

According to the data, Figure 1 shows that no students could answer correctly in the test item B when the participants were introduced with the pre-test. However, more than $40 \%$ of students answered 4 questions correctly, and over 50\% of students successfully answered 3 questions, and some $7 \%$ of students had only 2 correct answers. 


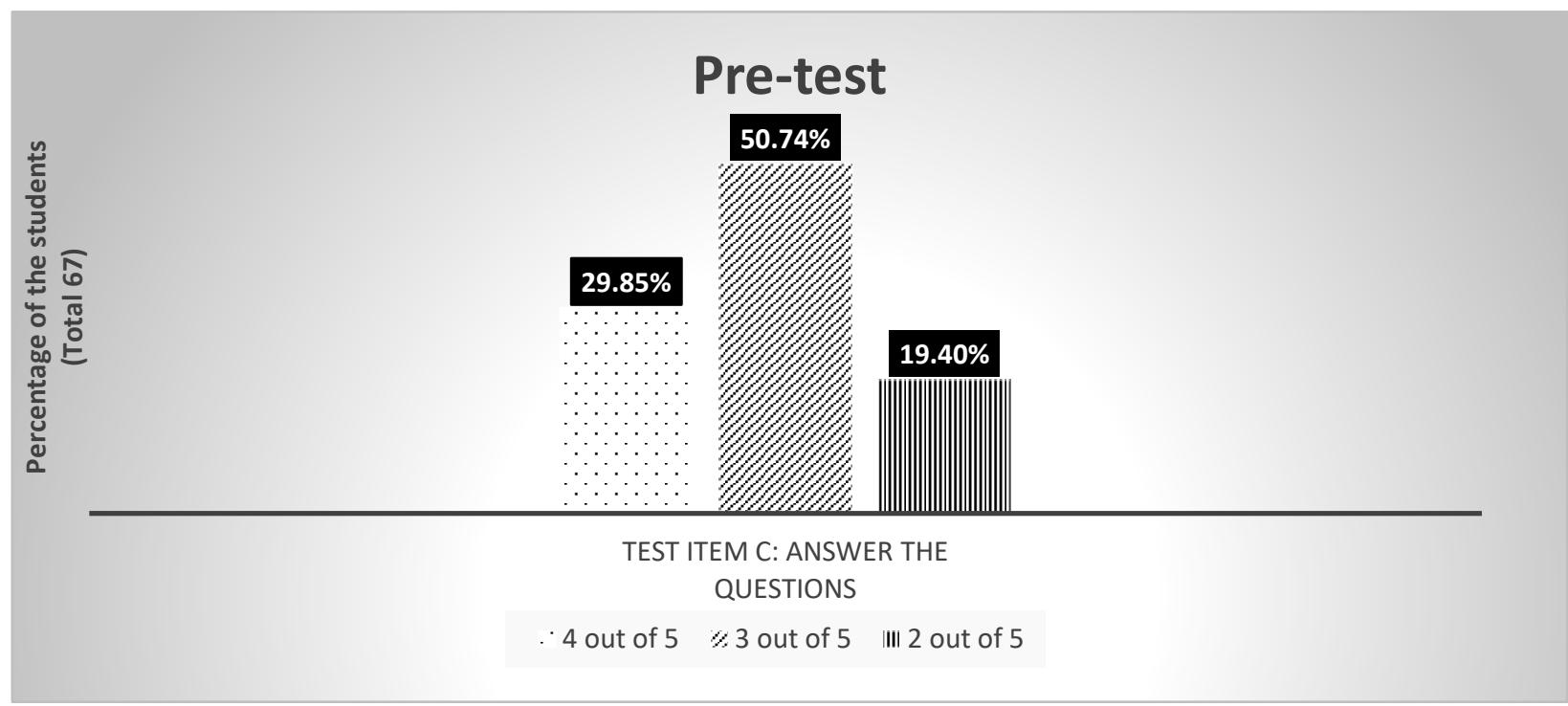

Figure 2: Students' performance regarding their ability to answer correctly in the pre-test: Test item C:

The performance for the test item $B$ in the pretest is even lower. According to Figure 2, not even 30\% (29.85\%) students had 4 correct answers. Though more, than $50 \%$ of the total students corrected 3 answers from
5 and some $19 \%$ of the total students had corrected 2 answers. It is needed to mention that there were no 5 out of 5 correct answers in this test item as well.

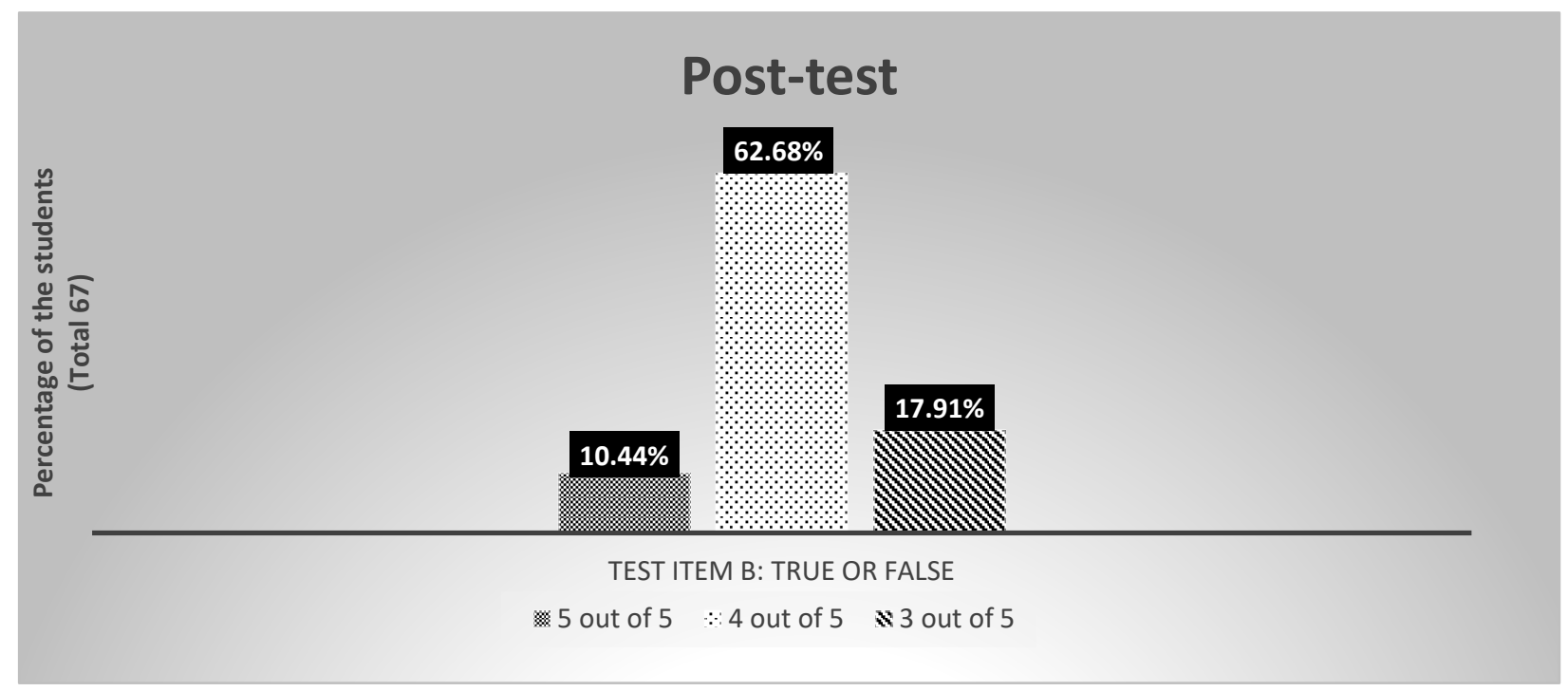

Figure 3: Students' performance regarding their ability to answer correctly in the post-test: Test item B:

However, the scenery has a significant change in the post-test. According to Figure 3, it was found that in the test item $\mathrm{B}$, almost $11 \%$ of students were successful in answering all the 5 questions. And almost $63 \%$ were able to answer 4 questions correctly. The rest of the students answered 2 questions correctly. 


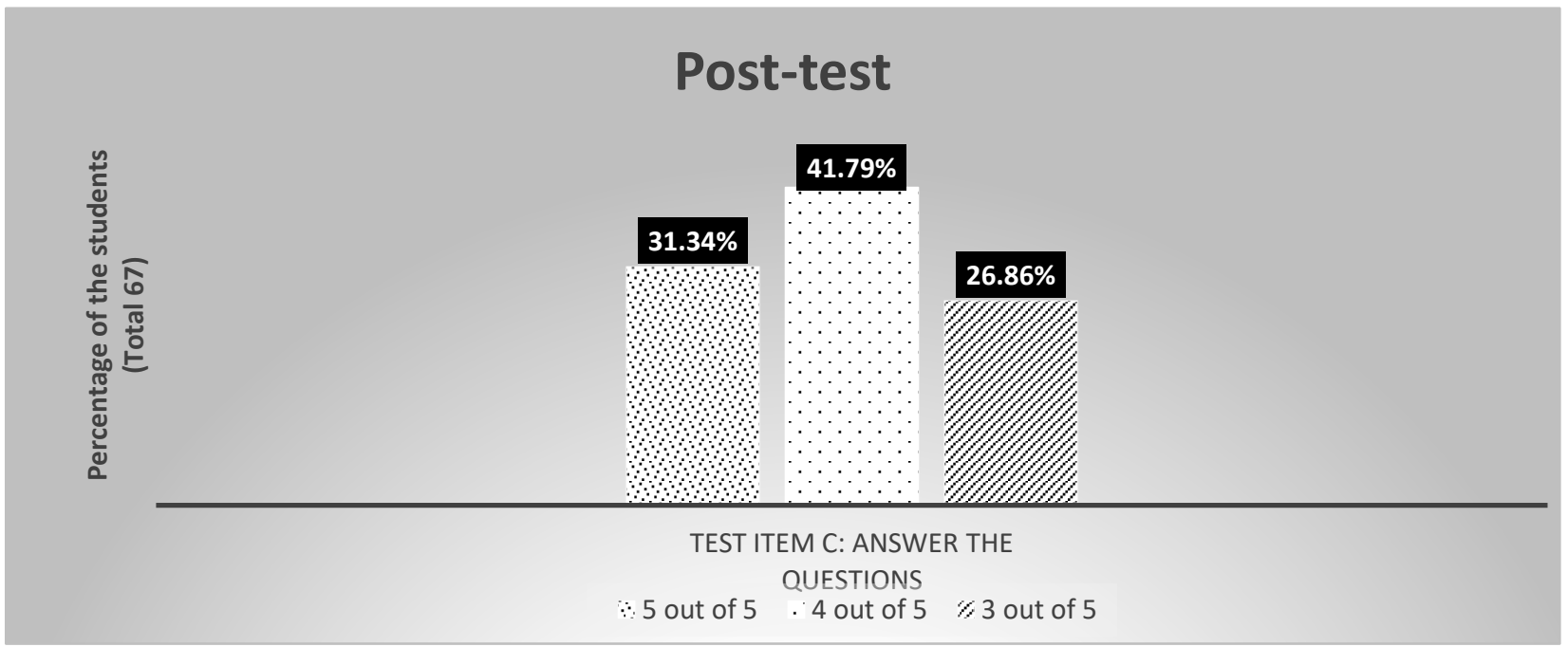

Figure 4: Students' performance regarding their ability to answer correctly in the post-test: Test item C:

For the test item $\mathrm{C}$ in the post-test, the 4 correct answers, and the rest of them (29.63\%) were difference is more graphic. According to Figure 4, successful in answering at least 3 questions.

almost $30 \%$ of students scored 5 out of 5 , over $40 \%$ had

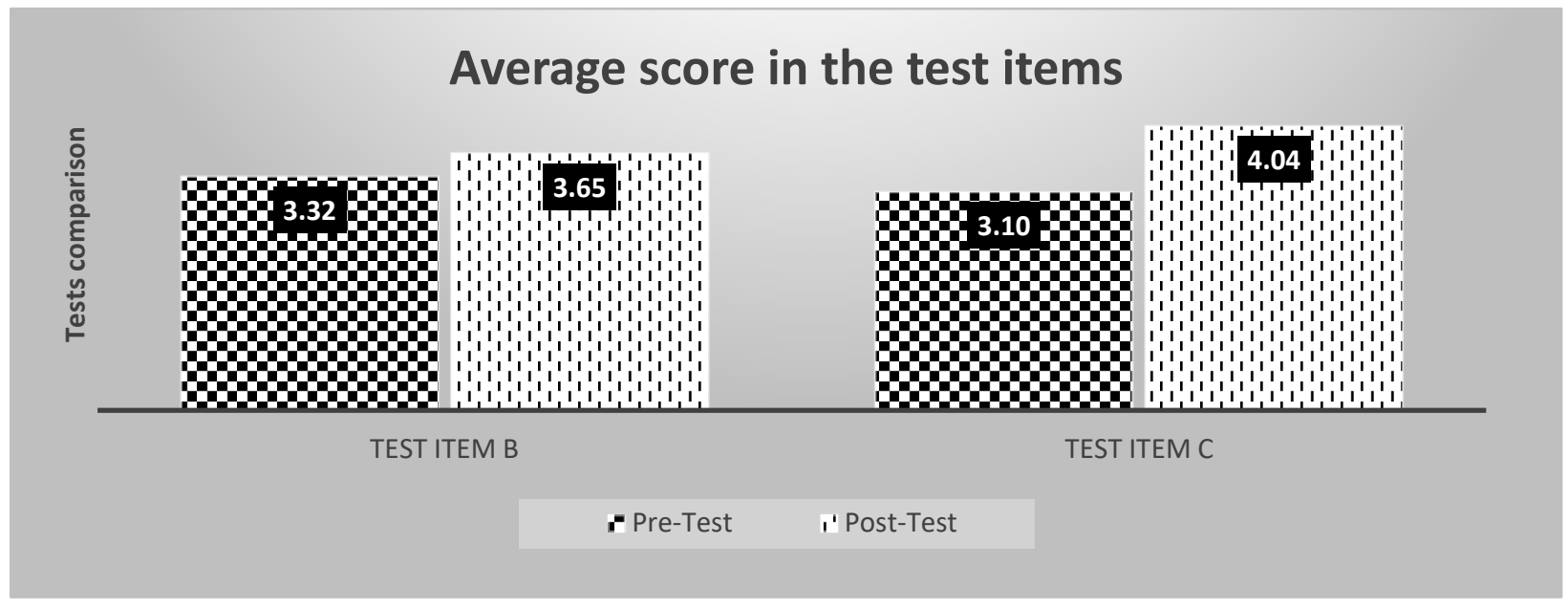

Figure 5: Comparison of the tests: Average score in the test items

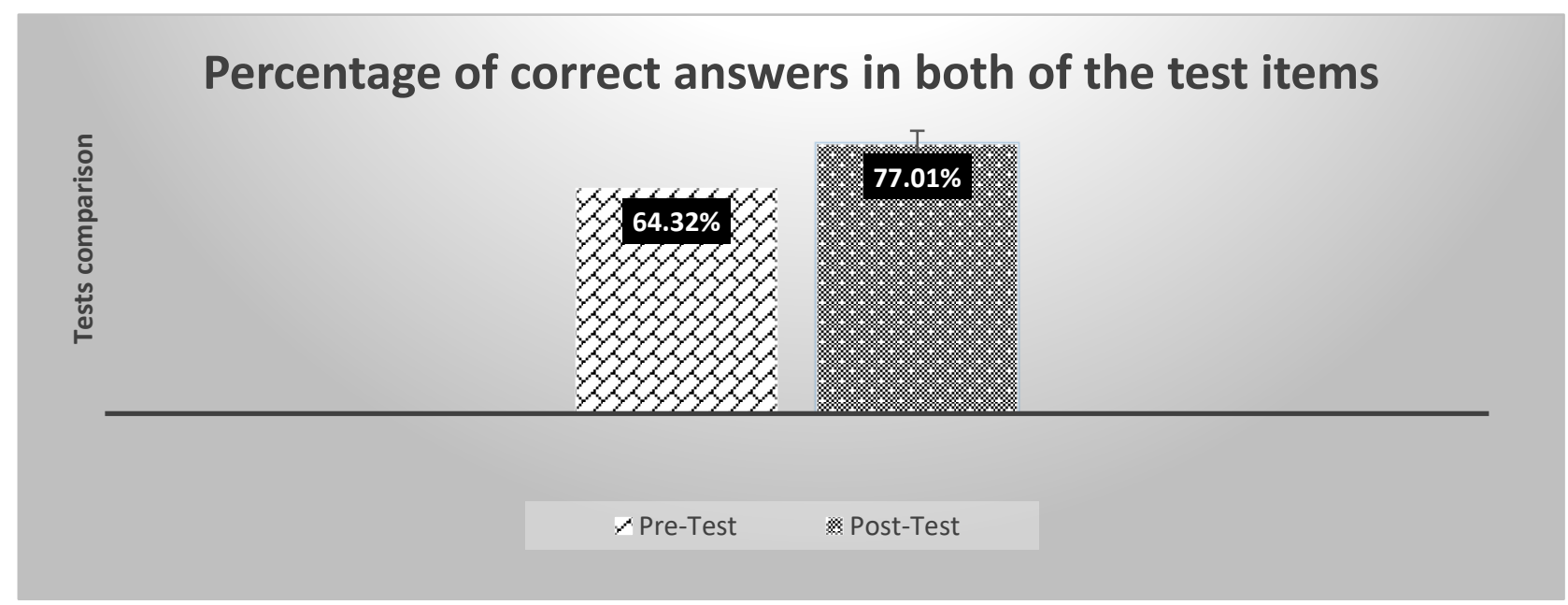

Figure 6: Comparison of the tests: Percentage of correct answers 
According to Figure 5, when the tests were compared, it was found that in the pre-test, participants' average score was 3.32 in the test item B and 3.10 in the test item $\mathrm{C}$ whereas in the post-test the average score turned to 3.65 for the test item B and 4.04 in the test item $\mathrm{C}$. And Figure 6 shows that the percentage of correct answers in the pre-test was $64.32 \%$ and $77.01 \%$ in the post-test.

\section{Results \& Discussions}

Focusing on the data, especially from Figure 5 and Figure 6, the outcome clearly stated that students performed better when they had interacted. So, it is safe to say that interaction helped the students to comprehend reading lessons. The data reflected the benefit of interaction. According to the data, the percentage of correct answers was $64.32 \%$ in the pretest. And the percentage ratio rose more than $12.69 \%$ in the post-test to reach $77.01 \%$ after the introduction of interaction through pair work in the post-test. We can also see the positive deviation in the average rate of correct answers for both of the test items. In test item B, the average score increased to 3.65 in the post-test from 3.32 in the pre-test. The consistently same thing happened in test item $\mathrm{C}$. The average score turned to 4.04 in the post-test, whereas in the pre-test, it was 3.10. It also needs to mention that whereas there was no record of 5 out of 5 correct answers in the pre-test for both of the test items, $10.44 \%$ participants in the test item B and $31.34 \%$ participants in the test item C answered all (5 out of 5) questions correctly. These statistics showed that better learning and more comprehensible input took place during reading comprehension lessons as peer interaction was introduced. The result also proved that interaction helped the participants to raise their performance and comprehension level, which helped them to answer more questions correctly.

This study highlighted many issues regarding interaction and its facilitation in reading comprehension lessons, but there are some limitations of this study. Considering the length of this study, only pair-work (peer-interaction) was introduced as the form of interaction. Other forms, such as group-work, wholeclass interaction, were skipped. Besides, this study only considered the students of class VII, other classes were overlooked. Considering the classroom context, it was found that the students were not familiar with the interaction. So, it was a challenge for the researcher to introduce interaction while conducting the classes. Another important issue was the culture. The interaction created a noisy atmosphere in the classroom, which is not a typical Bangladeshi classroom, and that led the students to gossip, play, and to do other work which might bring some negative reinforcement in the study.

\section{ReCOMmendations}

This study so far recognized the role of interaction to facilitate comprehensible input in reading comprehension lessons. Students' performance regarding comprehension-based questions is very auspicious and leads toward further implications. As it helped the elementary classes towards their development in reading comprehension, it can be developed and introduced in the upper elementary classes as well. Besides, this study concentrated only on the EFL classes, which might be expandable to the ESL classes and even other language development classes as well. Also, as this study has a clear succession rate towards developing reading skills, it can be said that interaction can also be introduced for developing writing, speaking, and listening skills. In this study, the participants were the students of Bangla medium, and their success rate recommends the application of interaction in other media as well. This study also proposes the application of interaction in other parts of Bangladesh as the EFL classrooms are similar.

\section{Conclusion}

Reading does not only mean to read through the lines and to recognize letters but also means to understand. That is why it is very important to make a text comprehensible in a reading development class. This study framed interaction to examine its credibility for developing reading. Though there were some minor limitations, this study clearly showed the significance of interaction in a reading comprehension class. Besides, Krashen (1987, p31) defines interaction as an important part of a class as he considers interaction helpful for the students to lower their affective filter. Oliver (2009, p136) observes that the learners not only attain input through interaction but also produce comprehensible output. However, considering the role of the English language and the role of reading to learn the language in the Bangladeshi context, interaction can be one of the major tools for the stakeholders. Successful integration of interaction in the ELL or EFL classrooms will give the students more exposure to communicate in the language.

\section{References Références Referencias}

1. Ellis, R., (1985) Understanding Second Language Acquisition, Oxford: Oxford University Press.

2. Ellis, R., (1994) The Study of Second Language Acquisition, Oxford: Oxford University Press.

3. Ellis R., Tanaka $Y$ and Yamazaki A (1994), "Classroom interaction, comprehension, and the acquisition of L2 word meanings". Language Learning 44: 449-491. 
4. Ellis, Nick, (2009), "The psycholinguistics of the interaction approach", in Mackey, Alison \& Polio, Charlene Multiple Perspectives on Interaction: Second language research in honor of Susan M. Gass, New York: Routledge.

5. Harmer, J., (2007) The Practice of English Language Teaching, $4^{\text {th }}$ edn., UK: Pearson Education Limited.

6. Khatib M, Alemi M and Daftarifard P (2010), "On the relationship between input and interaction psycholinguistic, cognitive, and ecological perspectives in SLA" BRAIN. Broad Research in Artificial Intelligence and Neuroscience 1(4): 59-68.

7. Krashen, S., (1981) Second Language Acquisition and Second Language Learning, Oxford: Pergamon Press.

8. Krashen, S. D. \& Terrell, T. D., (1983)The Natural Approach: Language Acquisition in the Classroom, Hayward: Alemany Press.

9. Krashen, S., (1985) The Input Hypothesis: Issues and Implications, London: Longman.

10. Krashen, S., (1987) Principles and Practice in Second Language Acquisition, New York: PrenticeHall International.

11. Long, Michael, (1996), "The role of the linguistic environment in second language acquisition. in Ritchie, William C., \& Bhatia, Tej k. Handbook of second language acquisition, New York: Academic Press.

12. MacLeod, Gordon, \& Maclntyre, Donald, (1977), "Towards a model for microteaching" in Mclntyre,
Donald, MacLeod, Gordon \& Griffiths, Roy Investigations of Microteaching, London: Croom Helm.

13. Oliver, Rhonda, (2009), "Investigating negotiation of meaning and feedback in children aged five to seven years", in Mackey, Alison \& Polio, Charlene Multiple Perspectives on Interaction: Second language research in honor of Susan M. Gass, New York: Routledge.

14. Pica, T. (1994), "Research on negotiation: what does it reveal about second language learning conditions, processes and outcomes?" Language Learning 44: 493-527.

15. Salazar Campillo, P (1996), Comprehensible input and learning outcomes. Available at: http://hdl. handle.net/10234/80406 (accessed 3 March 2017).

16. Smith \& Johnson (1978), Definition of Reading Comprehension. Available at http://www.scholastic. com/teachers/article/understanding-reading comprehension (accessed 3 May 2014).

17. Van Lier, L., (2004) The Ecology and Semiotics of Language Learning: A Socio cultural Perspective, Boston: Kluwer Academic Publishers.

18. Vygotsky, L.S., (1978) Mind in Society, Cambridge: Harvard University Press.

19. Yule, G.,(2006)The Study of Language: An Introduction, New York: Cambridge University Press.

\section{Appendix A}

Pre-test: Comprehension based reading passage with test items which was conducted after classroom observation:

A. Read the passage carefully. Then answer the following questions.

Many years ago, Mr. and Mrs. Brown lived in England. During the Second World War, in March, 1944 a bomb landed on Mr. and Mrs. Brown's house. They lost their house and all their belongings. After the war, in August 1947, they left England and went to Australia. They decided to live there. One day Mr. and Mrs. Brown were at their new home in Sydney. Mrs. Brown was looking sad. "Why are you looking so sad?" Mr. Brown asked Mrs. Brown. "I've just read a very sad book." Mrs. Brown replied. "What's it called?" asked Mr. Brown. "The Diary of Anne Frank," Mrs. Brown replied. "I've never heard of it. What's this diary about?" asked Mr. Brown. "It's the diary of a young Dutch Jewish girl. She died in the war. It's a very sad story, but very interesting", Mrs. Brown replied. She also said "I found it in the library. It's a new book and they have only just received it."

B. Write whether the sentences are true or false. If true, write true. If false, write false and give the correct information.

1. Mr. and Mrs. Brown lost their house in 1944.

2. Mrs. Brown was very sad for her house.

3. Mrs. Brown was reading a diary in her new house in Sydney.

4. Anne Frank died in the Second World War.

5. Mrs. Brown found the book very interesting.

C. Answer the following questions according to the passage.

1. What happened during the Second World War?

2. Why did Mr. and Mrs. Brown leave England and go to Australia?

3. Why was Mrs. Brown so sad? 
4. Why is the "Diary of Anne Frank" a sad story?

5. Who is Anne Frank?

\section{Appendix B}

Post-test: Comprehension based reading passage with the same types of question items after the introduction of interaction:

A. Read the passage carefully. Then answer the following questions.

Eleven years ago Samira and Laila had an interesting conversation with Samira's parents. It was about the Liberation War of Bangladesh. They wanted to know about it. Samira couldn't remember much and Laila couldn't remember anything. So they asked Samira's parents some questions about it. Samira asked her mother, Mrs. Dewan if she had kept a diary in 1971, during the liberation war. Mrs. Dewan replied positively but also regrettably said that she had lost that. Laila asked Mrs. Dewan if she remembered any particular incident. Samira's mother remembered the horrible night during war when lots of shouts and bangs were outside. Mr. Dewan told them that on that particular night, they all hid under the bed and after the very night, they went to Laila's village. Mr. Dewan also added that they had lived with Laila's family two or three months. Laila wanted to know when the war ended. Mr. Dewan replied that the freedom fighters had to fight fiercely for nine months to achieve the glorious victory.

B. Write whether the sentences are true or false. If true, write true. If false, write false and give the correct information.

1. Eleven years ago,the Liberation war was held.

2. Samira's mother lost her diary.

3. Mr. Dewan left their village in the night.

4. Samira's family stayed with Laila's family two or three months.

5. Mr. Dewan fought nine months to become victorious in the liberation war.

C. Answer the following questions according to the passage.

1. What was the conversation about that happened eleven years ago?

2. What happened to Mrs. Dewan's Diary?

3. Why did Samira's family go to Laila's village?

4. How long did the liberation war continue?

5. How did the freedom fighters get the victory? 